Андрей Паткуль

\title{
ЗАМЕЧАНИЯ К СТАТЬЕ ВЯЧЕСЛАВА МЕЛАСА «ПРОБЛЕМА СУЩЕСТВОВАНИЯ И ПРИНЦИП ДОПОЛНИТЕЛЬНОСТИ ФИЛОСОФСКИХ КАТЕГОРИЙ»
}

1) Первое, что смутило меня в Вашем тексте, это то, что Вы называете восприятие, принятие, поддержку и т. д. категориями. Но термин《категория» имеет вполне определенное формальное значение в философии, как мне представляется, - это наивысшие роды, которые сказываются обо всех более низких понятиях и даже индивидах, но сами уже не выступают субъектом более общей предикации. Мы, конечно, можем сказать, что о каждой из категорий сказывается понятие «сущее». Но, как учит нас Аристотель, такое сказывание будет омонимичным, сделанным по аналогии. Так что, я думаю, Вам нужно либо обосновать, почему эти термины Вы называете именно категориями, а не понятиями, феноменами или пр. (и в каком именно смысле Вы о них так говорите), либо, может быть, придумать им какое-то иное общее название. Как, например, Тенгели говорит об экспериенциалах. Во всяком случае, мне резануло слух такое употребление термина «категории».

2) Одна из ключевых затрагиваемых Вами проблем - это проблема соотношения «бытия» и «существования». В принципе, каждый автор волен придавать терминам то значение, которое он считает нужным и которое ему удобно. Но, во-первых, имеется некоторая история осмысления корреляции этих понятий, и ее, как мне кажется, стоит учитывать при написании статьи, а во-вторых, я хотел бы поделиться своим пониманием этого соотношения, которое отличается от того, которое Вы представляете в Вашей статье. Не знаю, пригодится ли это Вам. Но вдруг. Как мне кажется, «существование» это одна из модификаций «бытия», если можно так нестрого выразиться, частный его случай. А именно, существование - это бытие в наличии, действительность чего бы то ни было. Но бытие может иметь и другой смысл: например, бытие в качестве кого-то или чего-то. Мы, например, можем сказать, что Сократ есть философ, но не можем сказать, что Сократ существует (хотя некогда и существовал). Бытие Сократом предполагает бытие философом, разумным или смертным живым существом и т. д. Термин же «сущее» для меня означает все то, что в том или ином отношении есть. Мне кажется, так это и для Хайдеггера, тогда как «бытием» он называет то «быть», которое только мы, люди, понятные как Dasein, способны понимать, но которое само

\footnotetext{
${ }^{1}$ Паткуль Андрей Борисович - кандидат философских наук, доцент, Институт философии, Санкт-Петербургский государственный университет. a.patkul@spbu.ru
} 
не есть, подобно сущему (онтологическая дифференция). Кроме того, есть значительная проблема перевода терминов. Но все это может увести в тонкости, которые будут губительными для Вашего изложения.

3) Один из самых интересных моментов Вашей статьи в онтологическом отношении - это трактовка «существования», насколько я это понял, через принадлежность. Это очень интересно и требует отдельного развернутого обсуждения. Кроме того, подобный подход еще раз возвращает нас к вопросу о соотношении онтологии и математики, в том числе к перспективе замены philosophia prima математикой, например теорией множеств, как это предлагает Ален Бадью. Особый вопрос - это Ваш тезис о том, что мир в целом (в котором только и возможны любые принадлежности) не существует, точнее нет смысла говорить о его существовании. Интуитивно, а отчасти и дискурсивно (потому что мир - как получается - это то, в чем нечто принадлежит чему-то иному (определенному миру), но само уже не принадлежит ничему), это понятно, но и требует более полной экспликации и обоснования. Во всяком случае, остается вопрос, можно ли быть/существовать, не принадлежа, или принадлежать, не будучи / не существуя. Я в своих онтологических исследованиях сам часто сталкивался с аналогичным, хотя и не точно таким же, вопросом: означает ли бытие нечто в качестве чего-то (Сократа в качестве человека) принадлежность этого нечто в качестве элемента некоторому множеству (Сократа множеству всех людей), как это трактует онтология, редуцирующая саму себя к теории множеств. На уровне описания или манипулирования вещами это решение очень просто, изящно и эффектно. Но на уровне исходного онтологического разбирательства оно вызывает сомнения, во всяком случае мотивирует переосмысление: Сократ есть человек, поскольку он человек, имеет форму человеческого, в нем воплощено человеческое. И только потому, что он уже человек, мы можем сосчитать его как элемент множества всех людей. Можно ли экстраполировать это рассуждение на проблему бытия в смысле существования - отдельный вопрос. Что мы тогда получим? Что существовать означает принадлежать множеству всего сущего? Тут есть, конечно, подвох, который нужно анализировать дальше.

4) Меня заинтересовало Ваше, скажем так, решение проблемы бытия через ассоциацию его с тем, что Вы называете принятием. Хотя как раз, как, во всяком случае, мне показалось, понятие «принятия» следовало бы раскрыть более подробно - и на теоретическом уровне, и на уровне показательных дескрипций. От этого многое может зависеть в рецепции Вашей концепции.

5) Наконец, я хотел бы поддержать Вашу основную идею о связи того, что Вы называете «категориями», с модификациями времени. Это очень интересно и перспективно. Возможно, в рамках статьи эти идеи изложены слишком схематично; но это понятно, поскольку объем статьи ограничен, а чтобы раскрыть эту тему достойным образом, потребовалась бы отдельная статья, 
как минимум. Как и в п. 4) моих замечаний, я бы рекомендовать провести более подробную «дедукцию» модусов бытия из определений времени и дать ей больше наглядных примеров. Хотя хорошие примеры уже есть, например из языка. Может, их можно расширить, например, обратившись к другим языкам - живым и мертвым. 